\title{
Electrospinning of ABS nanofibers and their high filtration performance
}

\author{
Shaohua Jiang ${ }^{1,3}$ (1) $\cdot$ Holger Schmalz ${ }^{1,2} \cdot$ Seema Agarwal ${ }^{1,2} \cdot$ Andreas Greiner $^{1,2}$
}

Received: 24 November 2019 / Accepted: 30 December 2019 / Published online: 23 January 2020

(c) The Author(s) 2020

\begin{abstract}
Acrylonitrile-butadiene-styrene (ABS) is a commercial polymer for widely industrial applications due to its good mechanical and physical properties. However, there are only countable reports regarding its fibers from electrospinning. Comprehensive investigation on its optimized electrospinning parameters is missing. Herein, ABS fibers with different fiber diameters were produced by electrospinning. The electrospinning conditions, including the solvents, solution concentrations and amounts of different salt additives, have been comprehensively investigated. The morphologies of electrospun ABS fibers are studied by scanning electron microscopy and Raman spectroscopy. Different fiber diameters and coating densities are applied for filtration applications, which showed excellent filtration performance. The filtration efficiency of up to $99 \%$, low pressure drop of $<30 \mathrm{~Pa}$, and high filtration quality factor of up to 0.477 are achieved from the electrospun ABS fibers coated on microfibrous polypropylene substrates. In addition, the electrospun ABS fibers also shows good thermal stability and other applications such as oil/water separation.
\end{abstract}

Keywords Acrylonitrile-butadiene-styrene fiber $\cdot$ Electrospinning $\cdot$ Filtration $\cdot$ Oil-water separation

\section{Introduction}

Acrylonitrile-butadiene-styrene (ABS) is a commercial terpolymer made by polymerizing acrylonitrile and styrene in the presence of polybutadiene. It has broad applications for light, rigid and molded products, such as piping, musical instruments, golf club heads, automotive body parts, wheel covers, enclosures, protective headgear and toys,

Electronic supplementary material The online version of this article (https://doi.org/10.1007/s42765-019-00026-7) contains supplementary material, which is available to authorized users.

Shaohua Jiang

shaohua.jiang@njfu.edu.cn

$\triangle$ Andreas Greiner

greiner@uni-bayreuth.de

1 Macromolecular Chemistry, Bavarian Polymer Institute, University of Bayreuth, Universitätsstraße 30, 95440 Bayreuth, Germany

2 Bavarian Polymer Institute (BPI), University of Bayreuth, Universitätsstraße 30, 95440 Bayreuth, Germany

3 Present Address: College of Materials Science and Engineering, Nanjing Forestry University, Nanjing 210037, China because of its good physical and mechanical properties, such as excellent chemical resistance, dimensional stability, impact-resistant and toughness [1,2]. Although ABS has been comprehensively investigated and applied in many areas, only countable studies on its fibers and applications in fiber morphology are available. Electrospinning is a facial technology to produce fibers with diameters in the range from sub-nanometers to tens of micrometers and electrospun fibers have been applied in almost all fields, including tissue engineering, composites, actuators, catalysts, filtration and sponges [3-17]. In 2014, ABS and ABS/zeolite composite fibers were firstly prepared by electrospinning technology, but the fibers have a broad diameter distribution and no application was presented [18]. In another report, pure ABS fibers and their conductive ABS/copper composite fibers were fabricated via electrospinning and electroless metal deposition, respectively [19]. However, comprehensive investigation on the formation of ABS electrospun fibers is missing in this report. Very recently, $N, N$-dimethylformamide (DMF), $N, N$-dimethylacetamide (DMAc), and tetrahydrofuran (THF), were reported as solvents for the electrospinning of ABS, and the obtained ABS electrospun fibers were used for air filtration [20]. The results indicate that the DMF and DMAc were suitable solvents for electrospinning, 
but there are still many beads on fibers. Additionally, the filtration results suggest a relatively high pressure drop and low quality factor which could be because of the beaded ABS fibers and the self-standing thick membranes.

Therefore, it is still necessary to find out optimized electrospinning parameters for the fabrication of beads-free electrospun ABS fibers and investigate the relationship between the fiber structures and filtration performance. In this work, we choose a mixture of dimethyl sulfoxide (DMSO) and chloroform $\left(\mathrm{CHCl}_{3}\right)$ as solvent for the electrospinning of ABS. The electrospinning parameters to achieve homogenous and beads-free ABS fibers are optimized. To decrease the pressure drop and obtain high filtration quality factor, a commercial microfibrous polypropylene substrate (MFPP) is used to coating a very thin layer of electrospun ABS fibers. With the above strategies, electrospun ABS fibers with fiber diameter in the range from hundreds of nanometers to several micrometers are obtained. The novel composite filters (ABS electrospun fibers on MFPP) also show high filtration efficiency, low pressure drop and high filtration quality factor.

\section{Experimental}

\section{Materials}

Acrylonitrile-Butadiene-Styrene (ABS, Novodur H701, $\mathrm{M}_{\mathrm{w}}=210 \mathrm{kDa}$, Styrolution Group GmbH), DMSO (99.5\%, Gruessing $\mathrm{GmbH}$ ), $\mathrm{CHCl}_{3}$ (99\%, Sigma-Aldrich), sodium dodecyl sulfate (SDS, 99\%, Sigma-Aldrich) and perfluorodecalin (oil, 95\%, density $1.908 \mathrm{~g} / \mathrm{mL}$, Sigma-Aldrich) were used as received. Pyridine-formic acid salt (PF) was prepared by mixing pyridine (99.9\%) and formic acid (98\%) (1:1 molar ratio). Microfibrous PP substrate (fiber diameter of $23 \pm 4 \mu \mathrm{m}$ ) was used for coating electrospun ABS fibers. The commercial filter (MGK-P95\%, $90 \mathrm{~g} / \mathrm{m}^{2}$, thickness $0.5 \mathrm{~mm}$ ) was provide by Shanghai Mingguan Purification Materials Co., Ltd, which was prepared by melt-spinning.

\section{Preparation of electrospun ABS fibers}

The ABS solutions for electrospinning were prepared according to the component composition in Table S1. The ABS pellets were dissolved in mixture solvent of DMSO and $\mathrm{CHCl}_{3}$ (wt/wt, 1/1) with different concentrations. Different amounts of SDS were added to the ABS solution to adjust the conductivity of the solutions. Thirty-one ABS solutions (S1-S31) were prepared. The electrospinning was performed by applying a high voltage of $12-20 \mathrm{kV}$, collecting distance of $15-20 \mathrm{~cm}$ and flow rate of $0.6 \mathrm{~mL} / \mathrm{h}$. The samples for fiber morphology, pore size and heat resistance were prepared by collecting the fibers with aluminum paper on a horizontal rotating disc. The samples for the filtration and adhesion test were prepared by coating the fibers on polypropylene microfiber filter substrate for different lengths of time.

\section{Characterizations}

The electrospun fiber morphology was measured by scanning electron microscopy (SEM, Zeiss LEO 1530, $\mathrm{EHT}=3 \mathrm{kV}$ ). All the samples were coated with $3.0 \mathrm{~nm}$ platinum before scanning. The fiber diameter was measured by ImageJ software. The pore size of nonwoven electrospun ABS was measured by a pore size meter (TOPAS, PSM165). The filtration measurement for salt particles was performed on MFP 2000 from PALAS ${ }^{\circledR}$ with a white light-scattering spectrometer, Welas digital 2100 (particle size detection range: $0.2-10.0 \mu \mathrm{m})$.

A confocal WITec alpha $300 \mathrm{RA}+$ imaging system equipment with a UHTS 300 spectrometer and a back-illuminated Andor Newton 970 EMCCD camera was used for Raman imaging. Raman spectra were acquired using an excitation wavelength of $532 \mathrm{~nm}$ and an integration time of $0.7 \mathrm{~s}$ pixel $^{-1}(100 \times$ objective, NA $=0.9$, step size $100 \mathrm{~nm}$, software WITec Control FOUR 4.1). All spectra were subjected to a cosmic ray removal routine and baseline correction. The spatial distribution of SAN and PB particles in the fibers was determined by basis analysis using the Raman spectra of the neat components as references (software WITec Project FOUR 4.1). The neat Styrene-Acrylonitrile (SAN) and polybutadiene $(\mathrm{PB})$ particles were obtained by extracting ABS with acetone, which dissolves SAN selectively.

\section{Results and discussion}

\section{Electrospinning of ABS}

In previous reports, acetone and DMSO were used as solvents for electrospinning ABS $[18,19]$. However, there are disadvantages using these two solvents. Acetone has a low boiling point of $56.5^{\circ} \mathrm{C}$ and high vapor pressure of $24.6 \mathrm{kPa}$ $\left(20^{\circ} \mathrm{C}\right)$ [21], which lead to a fast evaporation during electrospinning. Therefore, ABS precipitates easily at the electrospinning nozzle, disturbing the continuous jet formation. By comparison, DMSO has a very high boiling point of $189^{\circ} \mathrm{C}$ and very low vapor pressure of $55 \mathrm{~Pa}\left(20^{\circ} \mathrm{C}\right)$ [21], causing deposition of wet fibers gluing together and losing fiber morphology. Chloroform is another common solvent for electrospinning. It has a slightly higher boiling point of $61.2^{\circ} \mathrm{C}$ and lesser vapor pressure of $21.1 \mathrm{kPa}$ than acetone [21]. Similar to acetone, it is also a good solvent for ABS. Our initial studies on the electrospinning of $\mathrm{ABS} / \mathrm{CHCl}_{3}$ solutions 
showed a blockage of the electrospinning nozzle due to the fast solidification of the solution at the nozzle tip. Therefore, in this work, a solvent mixture of DMSO and $\mathrm{CHCl}_{3}$ with equal weight ratio was used for the electrospinning.

The initial investigation was focused on the electrospinning of ABS solutions with high concentrations (S1: 25 wt\%, S2: $20 \mathrm{wt} \%$ and S6: $15 \mathrm{wt} \%)$. These three solutions showed very good electrospinnability with the continuous electrospinning process. The increased concentration is beneficial to eliminate the beads on the fibers, but the fiber diameter also increases (Fig. 1). The electrospun fibers from 25 to $20 \mathrm{wt} \%$ ABS solution showed bead-free fibers and the average fiber diameters were $2800 \pm 350$ and $2180 \pm 390 \mathrm{~nm}$, respectively. The $15 \mathrm{wt} \%$ ABS solution led to a quite different fiber morphology. Many beads were observed on the fibers and the average fiber diameter was decreased greatly to $598 \pm 254 \mathrm{~nm}$. Higher magnification SEM images showed that the fiber surface was rough with particles embedded in the fibers. These particles could be from the PB dispersed in the styrene-acrylonitrile matrix in ABS, which is inherent during ABS synthesis.

Confocal two-dimensional (2D) Raman imaging was performed in order to probe the spatial distribution of SAN and $\mathrm{PB}$ in the fibers. It can be clearly deduced from the color-coded 2D Raman images shown in Fig. 2 that the supporting fiber consists of SAN and the embedded particles correspond to the PB particles in the ABS.

Conductivity plays an important role in the electrospinning process and the fiber morphology. The addition of salts in the electrospinning solutions could change the conductivity significantly. In this work, we first investigated the

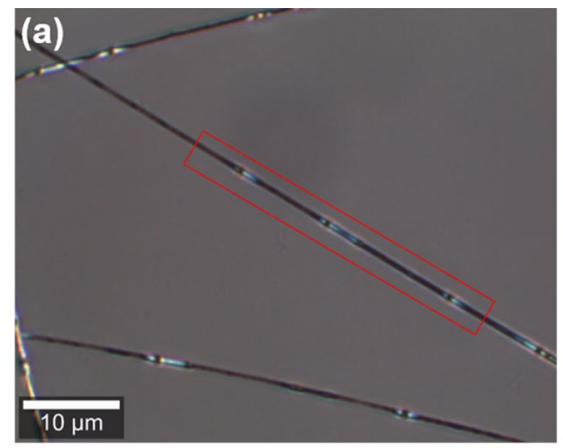

(d)
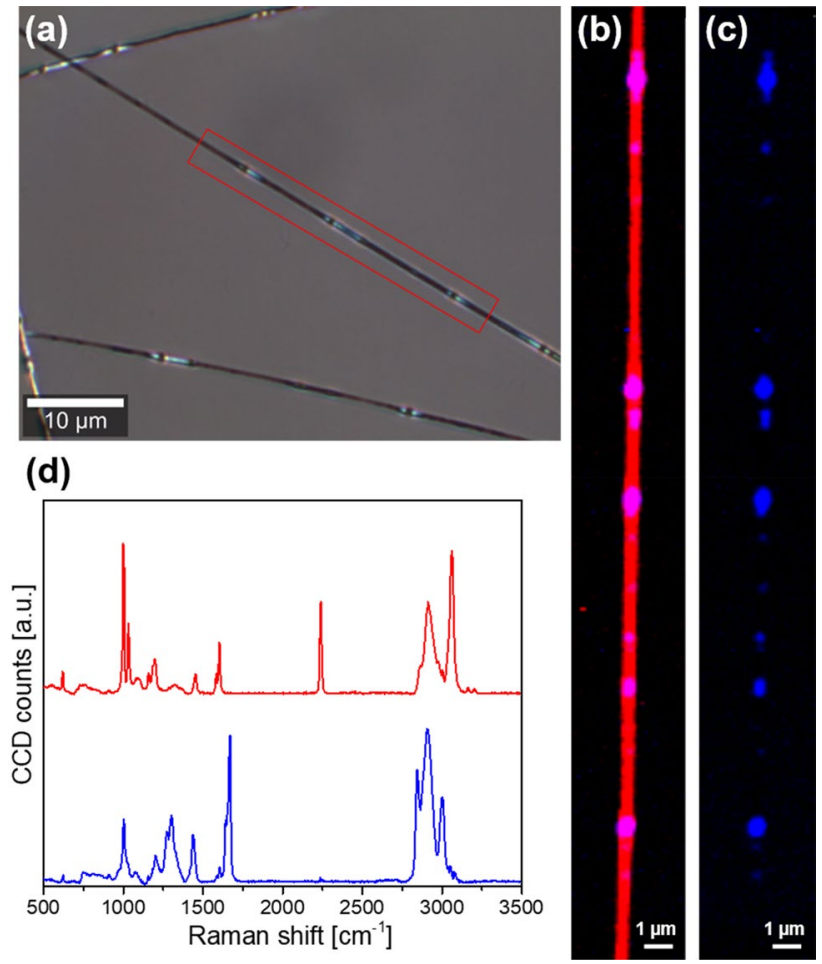

Fig. 2 Raman imaging of ABS fibers (sample S25). a Optical micrograph with marked position for Raman $\mathrm{x}$, y-imaging. b Color-coded confocal 2D Raman image showing the spatial distribution of SAN (red) and PB particles (pink) in the electrospun ABS fibers; $\mathbf{c}$ the distribution of $\mathrm{PB}$ particles (blue) for means of clarity. d Raman spectra of SAN (red) and PB particles (blue)
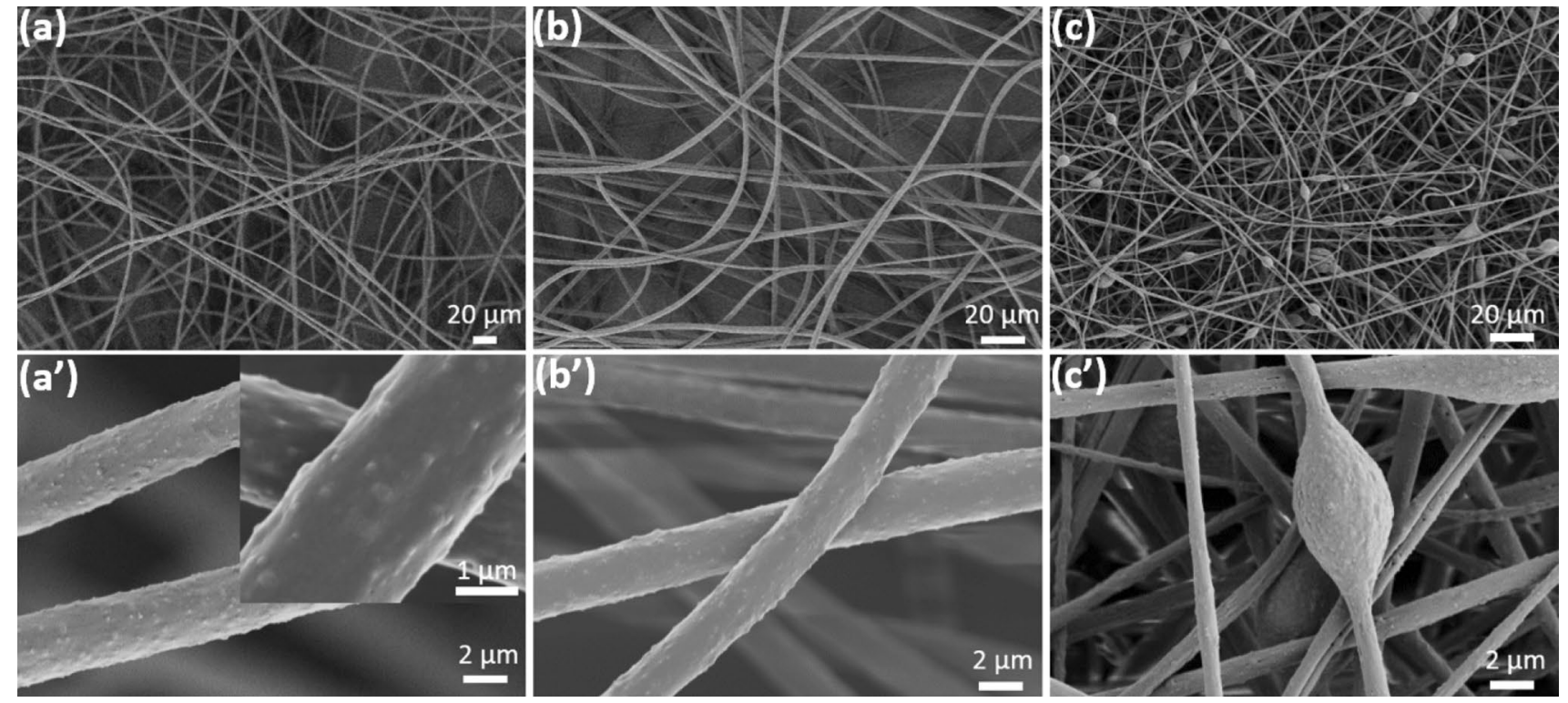

Fig. 1 Fiber morphology of electrospun ABS fibers spun from a mixture of DMSO: $\mathrm{CHCl}_{3}(1: 1 \mathrm{wt}$ : wt) with concentrations of 25 wt $\%$ (a, $\mathbf{a}$ '), 20 wt $\%\left(\mathbf{b}, \mathbf{b}^{\prime}\right)$ and $15 \mathrm{wt} \%\left(\mathbf{c}, \mathbf{c}^{\prime}\right)$ 


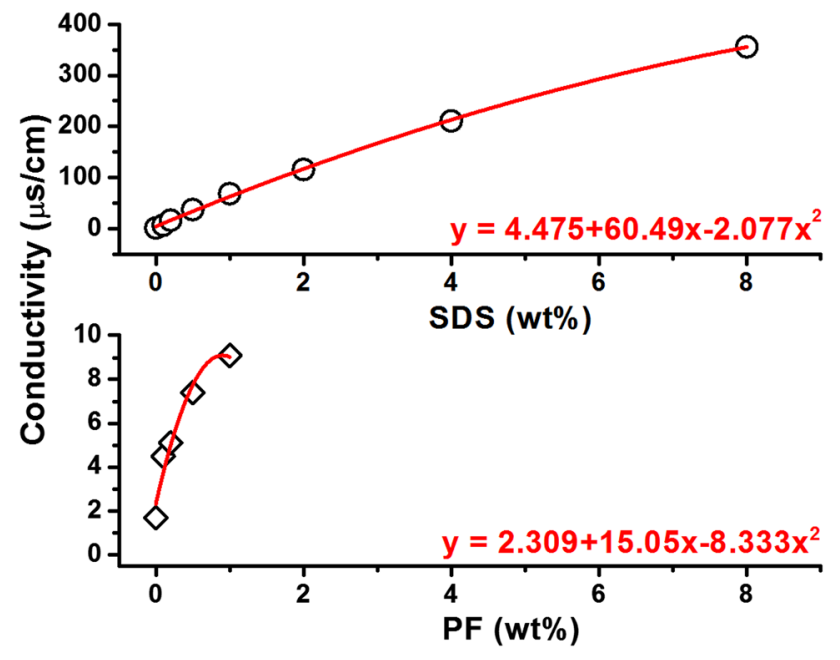

Fig. 3 Effect of salt additives (SDS and PF) on the conductivity of the ABS solution (20 wt \%)

addition of a small amount of SDS and PF on the solution conductivity, the electrospinnability and the fiber morphology. Figure 3 presents the relationship between the conductivity of ABS solutions (20 wt $\%$ ) and the added amount of SDS and PF salts. The addition of both SDS and PF into the ABS solutions could increase the conductivity, but SDS exhibits a much more obvious effect. With the addition of $1 \mathrm{wt} \%$, SDS increased the conductivity up to $68.5 \mu \mathrm{s} / \mathrm{cm}$, which was seven times more than that by adding PF $(9.1 \mu \mathrm{s} /$ $\mathrm{cm})$. A further increase of the amount of SDS led to greatly increased conductivity but also introduced the problem for the electrospinnability that big droplets were formed during the electrospinning process.

The addition of salts (SDS and PF) also affected the fiber morphologies significantly. Figure 4 shows the fiber morphologies electrospun from ABS solutions (20 wt\%) with different amounts of SDS from 0.1 to $8 \mathrm{wt} \%$ and PF from 0.1 to $1.0 \mathrm{wt} \%$. Compared to the fibers from the ABS solution without salt additives, the addition of salt is useful to decrease the fiber diameters. A small amount of SDS (0.1, 0.2 and $0.5 \mathrm{wt} \%$ ) led to a decrease of the fiber diameter to $1150 \pm 346,926 \pm 151$ and $908 \pm 208 \mathrm{~nm}$, respectively, which was half the diameter of the fibers from the solution without salts $(2180 \pm 390 \mathrm{~nm})$. Interestingly, this relatively high salt amount led to the fact that the fiber was branched with very fine fibers, which could be attributed to the strong repelling effect from the high conductivity. In comparison to the fibers from solution without additives, the addition of PF could also decrease the fiber diameter but not much more than the addition of SDS, which could be due to the weak effect on conductivity from PF (Fig. 4).

More solutions with different ABS concentrations and different amounts of salt additives of SDS and PF were prepared according to the Table S1 (1-5) to optimize the electrospinning conditions to achieve a good electrospinning process and obtain fibers with small diameters. The

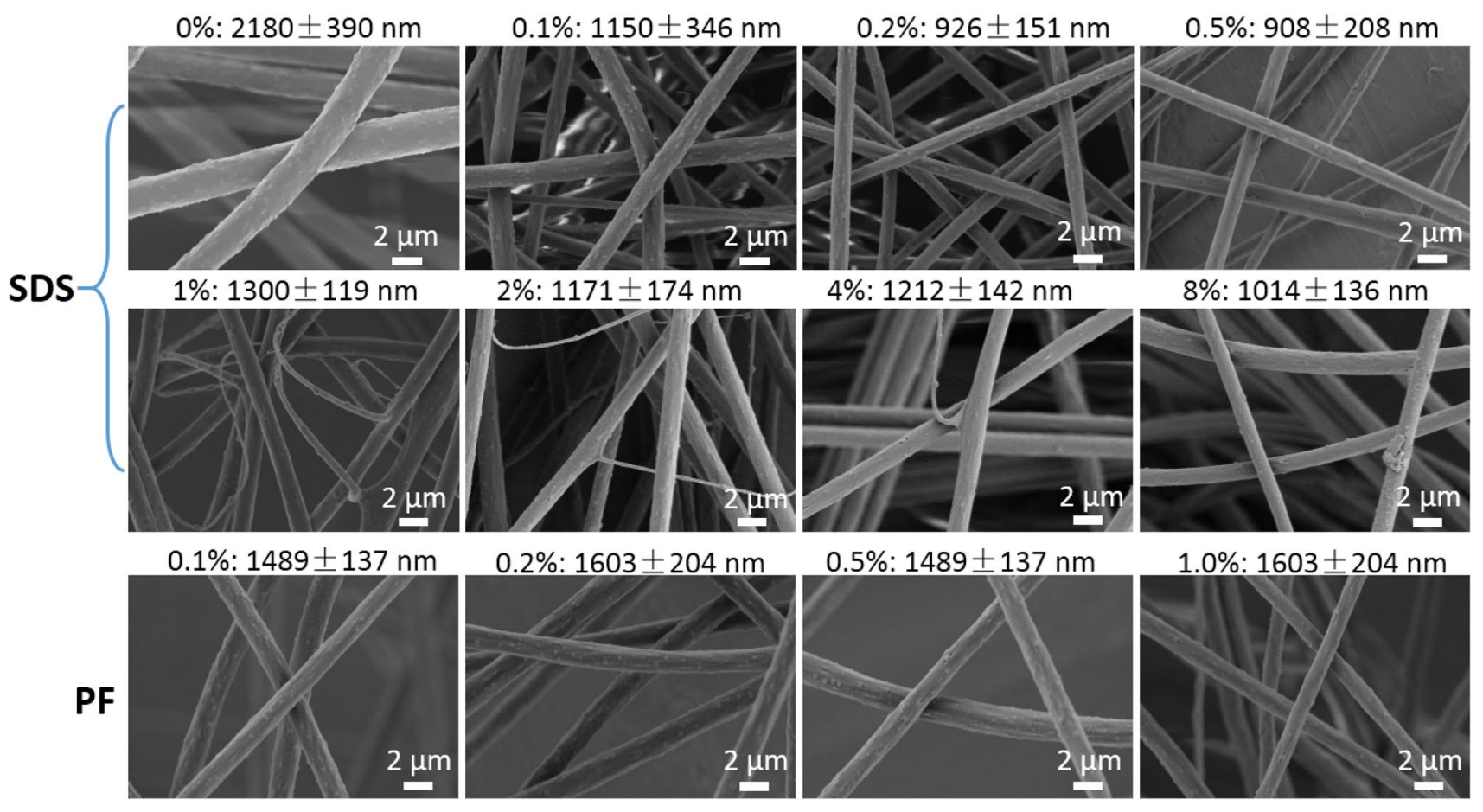

Fig. 4 Effect of the amount of SDS and PF on the fiber morphologies 


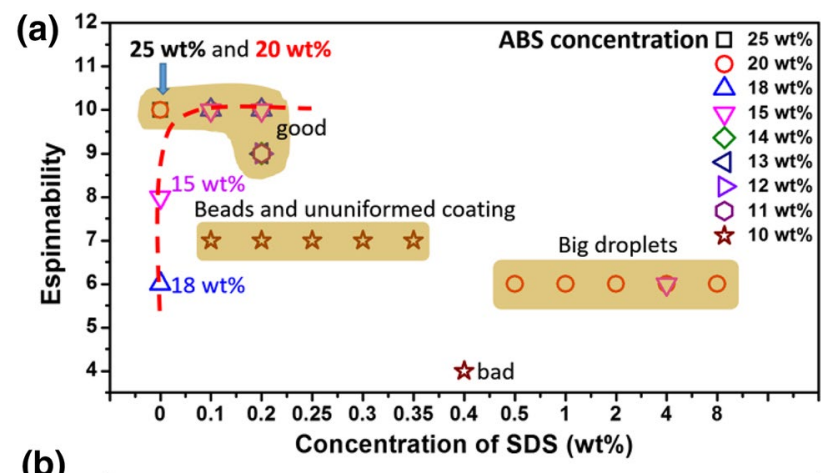

(b)

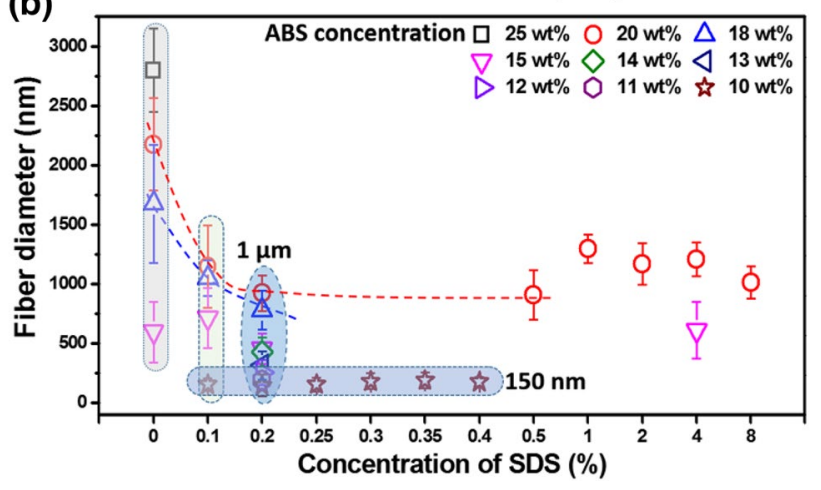

Fig. 5 The concentration of ABS and SDS on the electrospinnability (a) and fiber diameters (b). The electrospinnability was defined by rates: 10-very good; 9—good (a small number of beads); 8-good (many beads); 7-good (beads and ununiformed coating); 6-common (big droplets); and 4-bad (beads, big droplets and ununiformed coating)

cross effect of ABS concentration and additive amounts on the electrospinnability and fiber diameter is shown in Fig. 5. It is obvious that the fiber diameter decreases as the ABS concentration decreases ( $0 \mathrm{wt} \%$ SDS) and a small amount of SDS up to $0.2 \mathrm{wt} \%$ is useful to decrease the fiber diameter. Increasing the salt amount by more is not expected to further decrease the fiber diameter, but the fiber diameter is still much smaller than the fibers from a solution without salt. Fixing the ABS concentration to $10 \mathrm{wt} \%$ and changing the SDS amount $(0.1,0.2,0.25,0.3,0.35$ and $0.4 \mathrm{wt} \%)$ cannot change the fiber diameter much. However, by fixing the SDS amount to $0.2 \mathrm{wt} \%$ and changing the ABS concentration from $20 \mathrm{wt} \%$ to $10 \mathrm{wt} \%$, it is easy to get tunable fiber diameters from $1 \mu \mathrm{m}$ to $150 \mathrm{~nm}$ (Figure S1).

Due to the hydrophobicity of ABS, the self-standing porous electrospun membrane showed the efficient separation of oil and water. In this work, we also tried to find some applications for electrospun ABS fibers. The electrospun ABS fibrous membrane could be used for oil/water separation due to the hydrophobicity with a water contact angle of $130^{\circ}$ (Fig. 6, SI Video). The mixture with oil (perfluorodecalin, $3 \mathrm{~mL}$ ) and water (dyed with Rhodamine B, $9 \mathrm{~mL}$ ) was filled into the container equipped with $\mathrm{ABS}$ fibrous separator (thickness: $0.1 \mathrm{~mm}$; diameter: $15 \mathrm{~mm}$ ). After about $6 \mathrm{~min}$, the oil/water mixture separated. The clear oil dripped into the collector and the red water was kept on the top of the ABS filter. These findings made electrospun ABS fibrous membranes possible for oil/water separation.

\section{Pore size and coating density}

Pore size and coating density are very important parameters for achieving the high filtration efficiency when randomly oriented fibers are coated on a filter substrate. In this work, we first prepared electrospun ABS nonwoven fibers with different fiber diameters and then measured the pore size of these nonwoven fibers. Figure 7 a plots the relationship between the fiber diameter and the pore size. Interestingly, the fiber diameter showed a linear relationship with the average pore size. When the fiber diameter came down to $300 \mathrm{~nm}$ from $2800 \mathrm{~nm}$, the average pore size dropped dramatically to $2 \mu \mathrm{m}$ from $13.5 \mu \mathrm{m}$. If the fiber diameter decreases to $100 \mathrm{~nm}$, then the average pore size could drop to even about $1 \mu \mathrm{m}$. These fine fibers and small pore size would greatly improve the filtration efficiency.

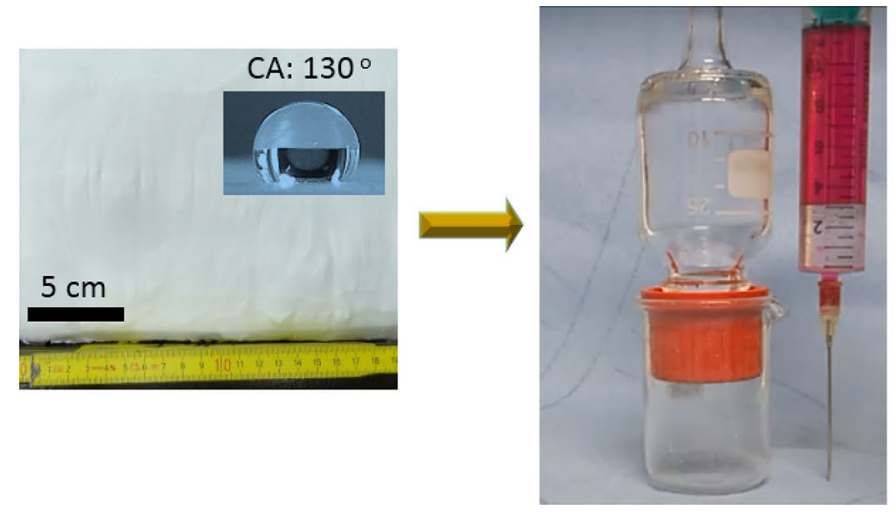

Red: Water

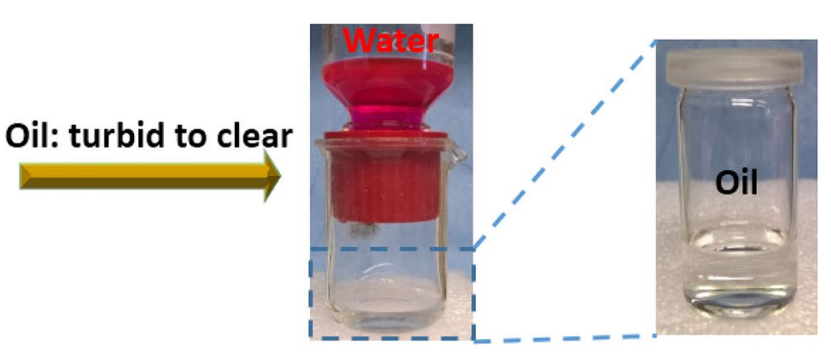

Fig. 6 Oil/water separation by electrospun ABS membrane 

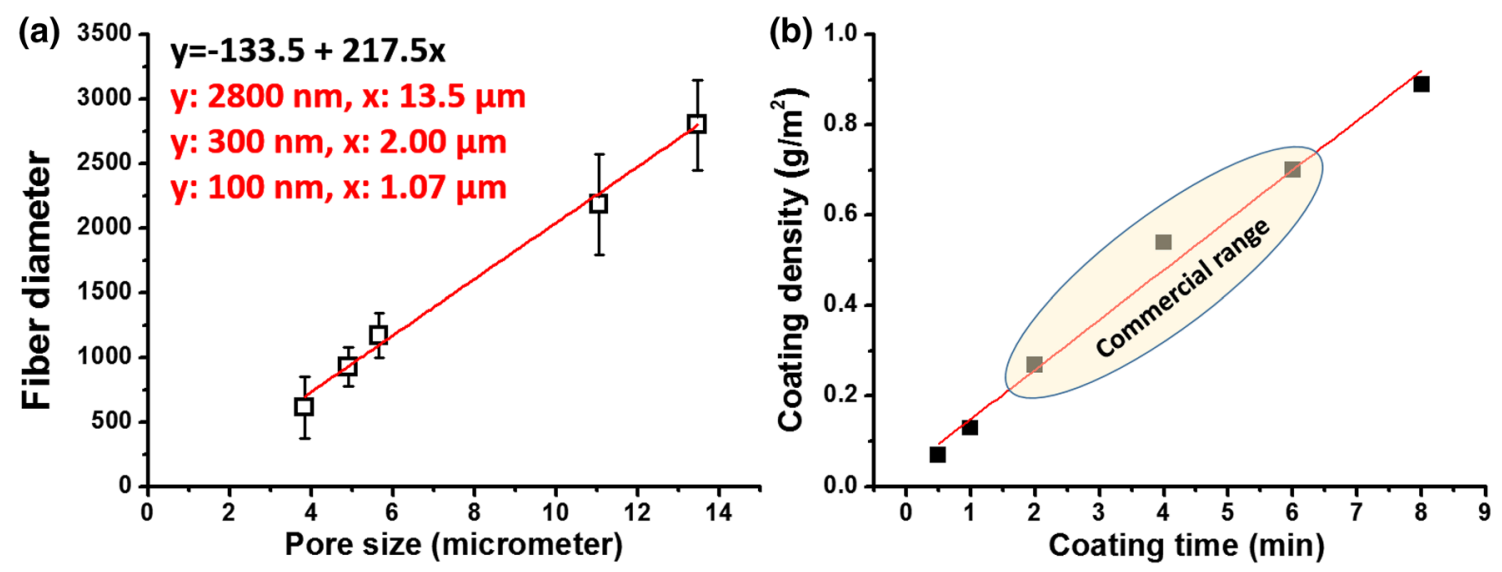

Fig. 7 Relationship of fiber diameter and pore size (a) and coating time-dependent coating density (b) of electrospun ABS fibers

Commercial filters usually have a coating of electrospun fibers with a weight per area in the range of $0.3-0.8 \mathrm{~g} / \mathrm{m}^{2}$. We established a simple method to measure the coating density (weight per area, $\mathrm{g} / \mathrm{m}^{2}$ ) of electrospun ABS fibers on MFPP $\left(9 \times 9 \mathrm{~cm}^{2}\right)$ : (1) Electrospinning ABS fibers on the substrates for different time (0.5, 1, 2, 4, 6 and $8 \mathrm{~min})$; (2) Drying the samples in a vacuum oven at $55{ }^{\circ} \mathrm{C}$ for $18 \mathrm{~h}$ to remove residual solvents; (3) Put the substrate with coating fibers on balance $(0.01 \mathrm{mg}$ deviation) and set weight to $0.00 \mathrm{mg}$; (4) Remove the coating fibers from the substrate; (5) Put the substrate on balance again and a minus value was obtained. The absolute value is the weight of the coating fibers on the substrate; (6) Repeat 4 times for each sample. Figure $7 \mathrm{~b}$ shows that the coating density was linearly increased with the coating time. When the coating time was 2, 4 and $6 \mathrm{~min}$, the coating weight per area was in the commercial range, which implied the commercial application of this coating filters.

\section{Heat resistance}

Due to the heat pressing process during the fabrication of filters, it is necessary to evaluate the heat resistance of electrospun ABS nonwovens. As shown in Fig. 8, the ABS nonwovens could stand the same shape under $110{ }^{\circ} \mathrm{C}$ for $2 \mathrm{~min}$. Higher temperatures led to the shrinkage of the nonwovens. The SEM images showed that no changes were found in the fiber morphology when the heating temperature reached around $110{ }^{\circ} \mathrm{C}$. When the samples were heated between 120 and $130{ }^{\circ} \mathrm{C}$, the fibers became smoother due to the melting of the dispersed polybutadiene particles. In addition, junctions between the fibers were also observed due to the partial melting of ABS fibers.

\section{Filtration efficiency}

The filtration measurement was performed to evaluate the effect of the electrospun fiber diameter and the coating time (coating density) on the filtration efficiency in comparison to the blank MFPP samples (MFPP-01 and MFPP-02) and the commercial filter (C-Filter). Before we measured the filtration efficiency, we first checked the fiber morphology of MFPP and C-Filter. As shown in Figure S2, the MFPP was composed of smooth fibers. The average fiber diameters are $23 \pm 4 \mu \mathrm{m}$ and junctions between the fibers were observed. A commercial filter contains two layers. One layer is a substrate layer with a homogeneous fiber diameter of $16.5 \pm 1.1 \mu \mathrm{m}$ and the other layer is composed of much thinner fibers with ununiformed fiber diameters of $1.3 \pm 1.2 \mu \mathrm{m}$. The two layers were glued together to improve the adhesion.

The electrospun fiber diameter and the coating density play a crucial role in the filtration efficiency of salt particles $(0.2-10 \mu \mathrm{m})$ (Fig. 9). As expected, the microfiber fibrous MFPP (MFPP-01 and MFPP-02) showed the worst filtration efficiency due to their large pore size. A coating of electrospun ABS fibers on the substrate improved the filtration efficiency. When fixing the coating time to $2 \mathrm{~min}$, the coating layer with a fiber diameter of $428 \mathrm{~nm}$ showed much better filtration efficiency than that with $2800 \mathrm{~nm}$ fiber diameter. The same results were also found when the coating time was fixed to 4 and $6 \mathrm{~min}$. Two exceptional samples were outside the rule of fiber diameter-related filtration efficiency. The first one is the sample coated with electrospun fibers of $598 \mathrm{~nm}$. This sample showed worse filtration efficiency than the sample coated with electrospun fibers of $2800 \mathrm{~nm}$, which could be due to the large beads on the fibers. Another exceptional sample was the filter coating with $149 \mathrm{~nm}$ ABS fibers, which showed very bad filtration efficiency among all coating samples. This could be due to the quite inhomogeneous coating on the 


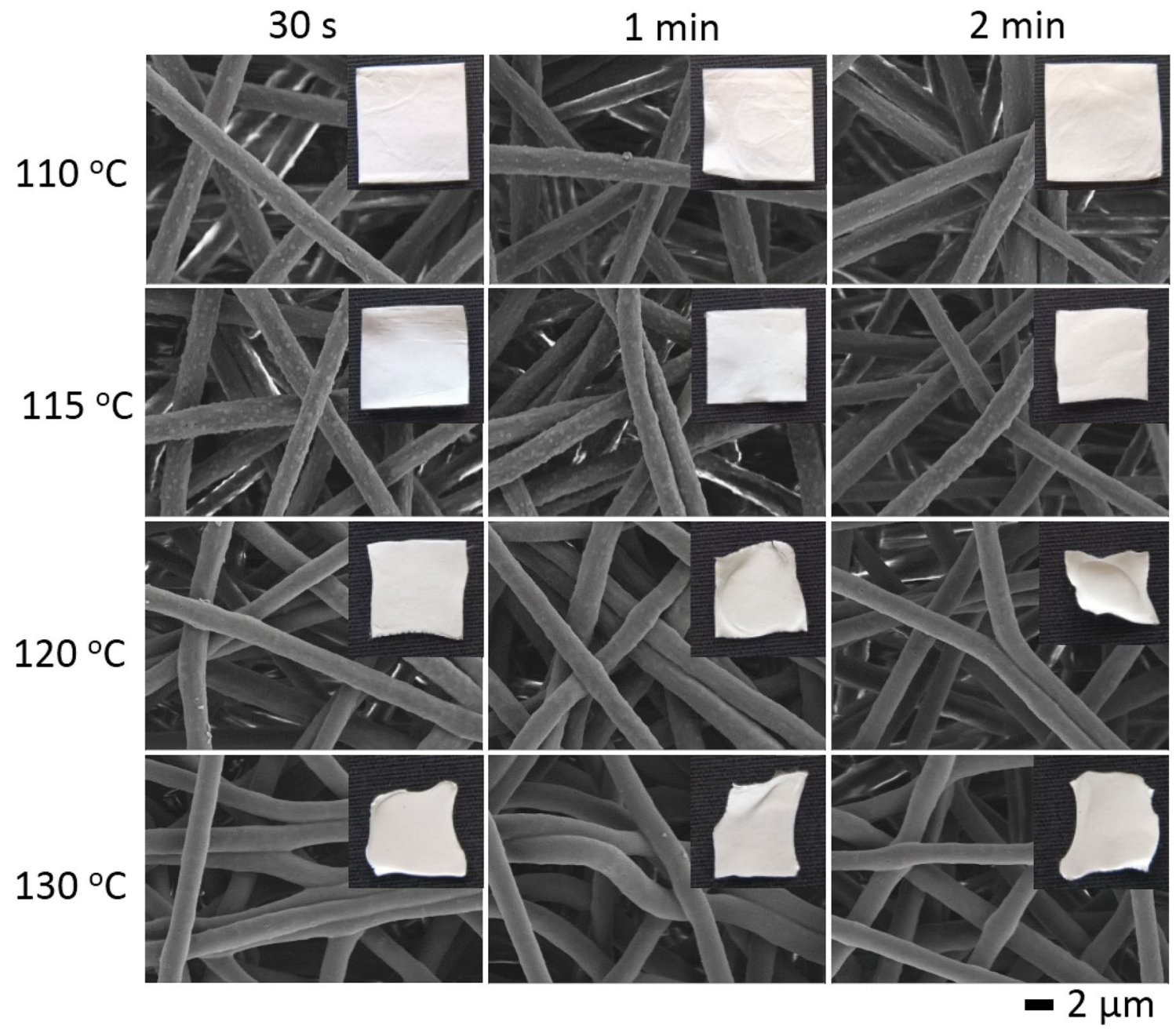

Fig. 8 SEM images of electrospun ABS fibers after heat treatment and photos (insert) of the heat resistance of electrospun ABS fiber nonwovens at different temperatures for different times. Sample: S6 with original size of $2 \times 2 \mathrm{~cm}^{2}$

MFPP (Fig. 9d). As the coating time (coating density) increased, the filtration efficiency also improved. When the fiber diameter was $428 \mathrm{~nm}$ and the coating time was $2 \mathrm{~min}$, the filtration efficiency was as good as the commercial filter (C-filter) with the particle size larger than $2.5 \mu \mathrm{m}$. When the coating time was $4 \mathrm{~min}$, the coated filter showed comparable filtration efficiency to the commercial filter and when the coating time was increased to $6 \mathrm{~min}$, the coating filter showed even better filtration efficiency than the commercial filter (Fig. 9).

Differential pressure (pressure drop) is an important parameter to evaluate the efficiency of filters. It is defined as the pressure difference between the two sides of the filter during the filtration test. Electrospun ABS fibers on MFPP, smaller fiber diameter and increasing the coating time generally lead to the increase of differential pressure (Fig. 10). Due to the large pore size, the MFPP showed the smallest differential pressure of $1.98 \mathrm{~Pa}$, while the commercial filter showed a differential pressure of 13.5 Pa. By comparison, the samples coated with 457 and $428 \mathrm{~nm}$ for 2 and $4 \mathrm{~min}$, respectively, which showed comparable filtration efficiency, presented similar or a little higher differential pressure.

Ashby figures of coating density-dependent pressure drop and the quality factor (QF) from different filter mediums were plotted to compare the quality of the filter prepared in this work to other filter mediums. As illustrated in Fig. 11, the filters in this work showed a much better filtration performance in terms of the pressure drop and QF. When comparing the pressure drop of different filter mediums (pressure drop $>30 \mathrm{~Pa}$ ), the ABS filters occupied a very important area where the small pressure drop $<30 \mathrm{~Pa}$ could be achieved with a sample coating density smaller than $0.8 \mathrm{~g} / \mathrm{m}^{2}$ (Fig. 11a). The quality of the filters could be evaluated by QF based on the comprehensive evaluation on the pressure drop and filtration drop. It can be calculated by the following equation: 
(a)

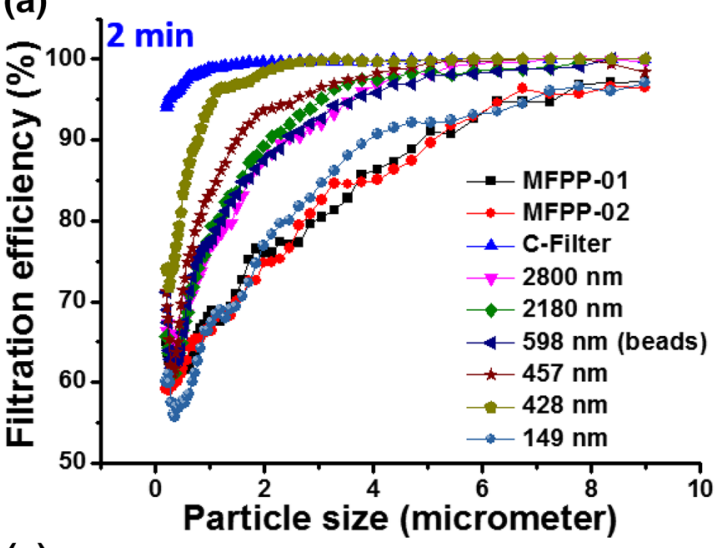

(c)

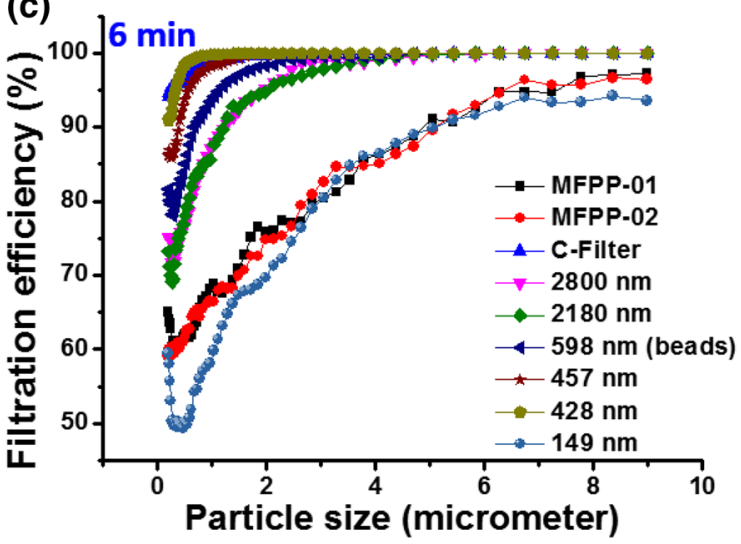

Fig. 9 Comparison of filtration efficiency of MFPP (substrate without coating), commercial filter (C-Filter) and the filters coating with electrospun ABS fibers with different fiber diameters and different (b)

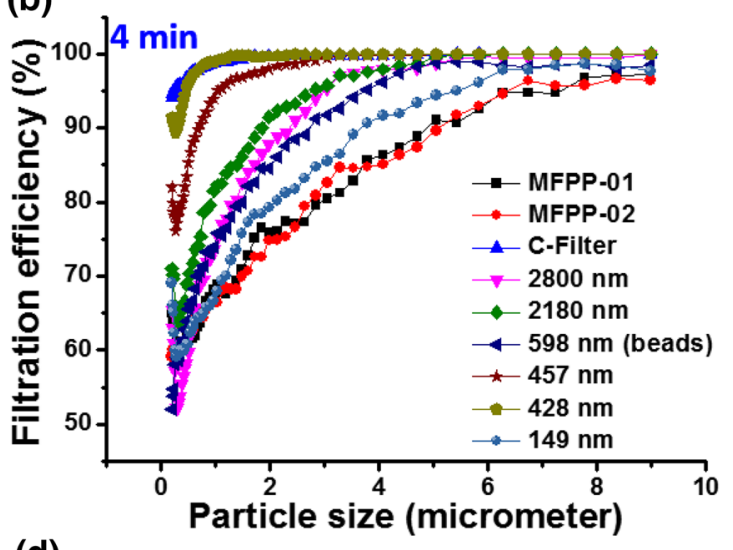

(d)

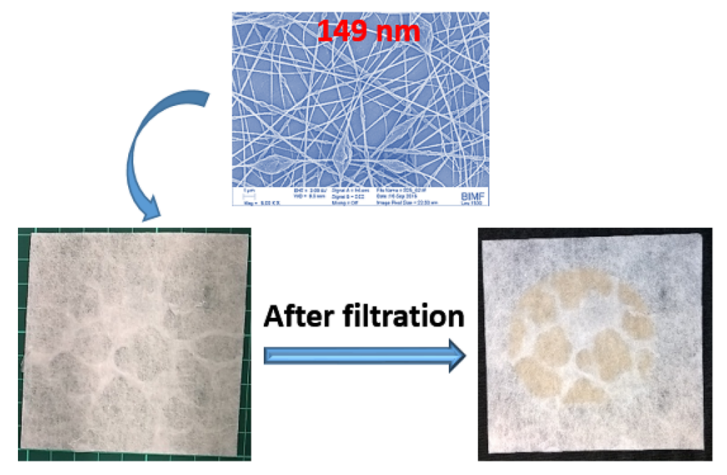

coating times of a $2 \mathrm{~min}, \mathbf{b} 4 \mathrm{~min}$ and $\mathbf{c} 6 \mathrm{~min}$. d Ununiformed coating with electrospun ABS fiber (149 nm) on MFPP before and after filtration
Fig. 10 Differential pressure of MFPP, commercial filter (C-Filter) and filters by coating electrospun ABS fibers with different fiber diameters and different coating times

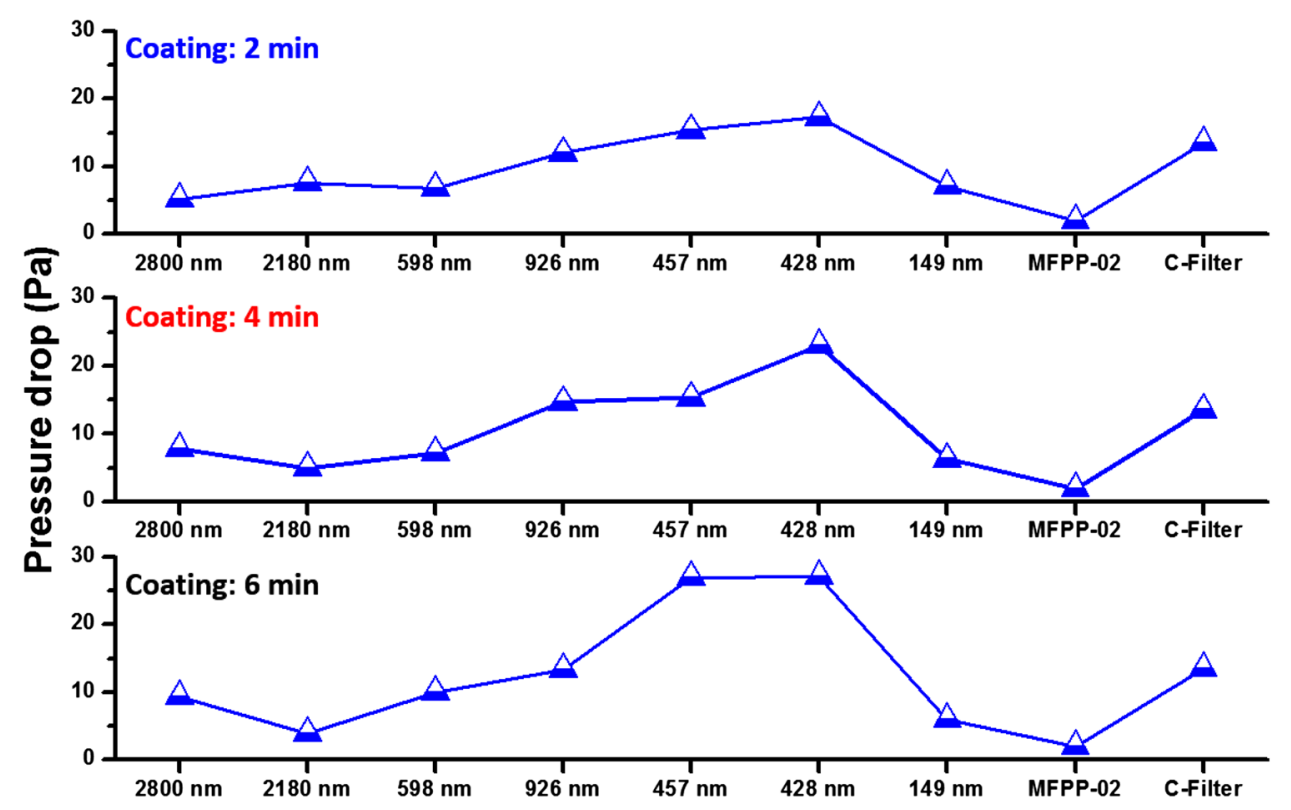



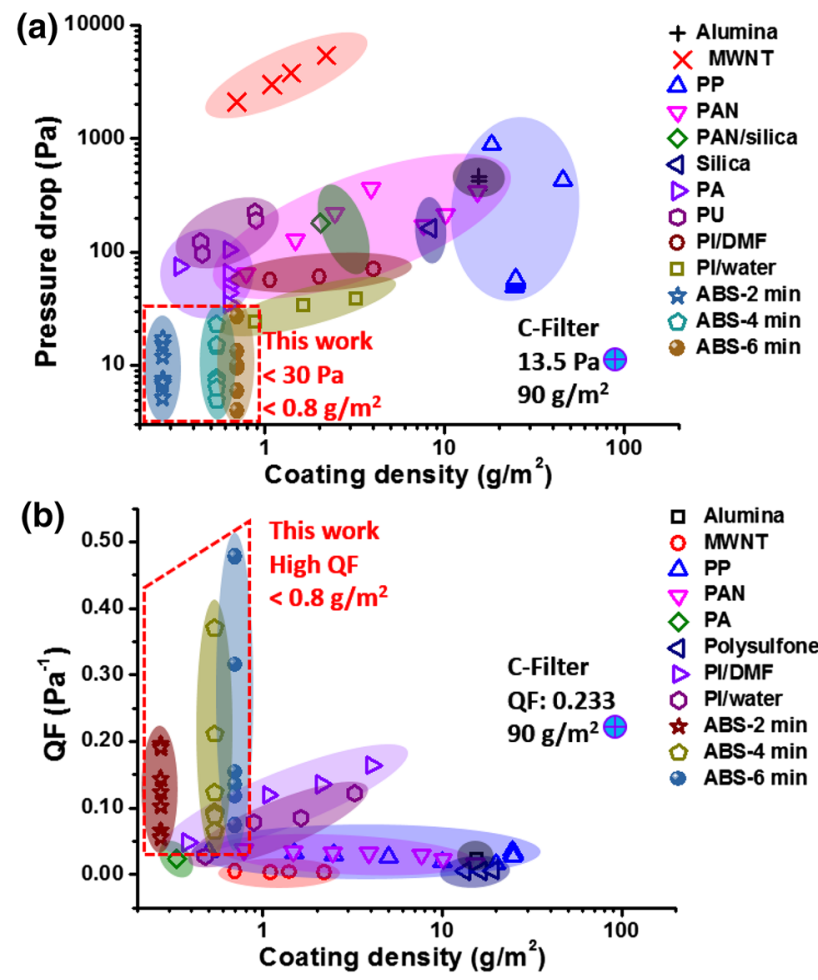

Fig. 11 Ashby plot of coating density-dependent pressure drop (a) and quality factor (QF) (b) for different filter mediums: Alumina [23], MWNT [22], PP [24-27], PAN [28, 29], PAN/silica [30], silica [31], PA [32, 33], PU [34], polysulfone [35] and PI [36]

$\mathrm{QF}=\frac{-\ln (1-\eta)}{\Delta P}$

where $\eta$ and $\Delta \mathrm{P}$ are the filtration efficiency and the pressure drop between the upstream and downstream pressure, respectively. The higher the $\mathrm{QF}$ is, the more efficient the filters are [22]. Figure 11b plotted the Ashby figure of QF for the $300 \mathrm{~nm}$ particle size in this work in comparison to other filter mediums. The ABS fibrous filters showed a tunable QF from 0.055 to 0.477 with a coating density $<0.8 \mathrm{~g} / \mathrm{m}^{2}$. This QF is larger than most other filter mediums in previous work. In addition, the pressure drop and QF of ABS fibrous filters are comparable to or even better than those of other filter mediums, suggesting these are ideal candidates as filter mediums for filtration applications.

\section{Conclusion}

In conclusion, commercial polymeric ABS can be processed into fibers by utilizing electrospinning technology and applied in the filtration area. By adjusting the concentration of polymer solution and changing the conductivity by adding SDS, ABS fibers with different diameters in the range of 200-2000 $\mathrm{nm}$ were successfully prepared by electrospinning. This electrospun ABS membrane showed thermal stability up to $110^{\circ} \mathrm{C}$ for $2 \mathrm{~min}$. Comparable filtration efficiency to commercial filter was achieved by coating electrospun ABS fibers on MFPP. The filtration efficiency improved as the fiber diameter decreased and the coating time increased. Compared to the commercial PA fiber filter, electrospun ABS fibers might be better electrically charged. Unfortunately, the adhesion between electrospun ABS fibers and MFPP was bad but could be improved by electrospraying glue or hot-pressing. The electrospun ABS fibrous membranes were also successfully applied for oil/ water separation.

Acknowledgments Open Access funding provided by Projekt DEAL.

\section{Compliance with ethical standards}

Conflict of interest There are no conflicts to declare.

Open Access This article is licensed under a Creative Commons Attribution 4.0 International License, which permits use, sharing, adaptation, distribution and reproduction in any medium or format, as long as you give appropriate credit to the original author(s) and the source, provide a link to the Creative Commons licence, and indicate if changes were made. The images or other third party material in this article are included in the article's Creative Commons licence, unless indicated otherwise in a credit line to the material. If material is not included in the article's Creative Commons licence and your intended use is not permitted by statutory regulation or exceeds the permitted use, you will need to obtain permission directly from the copyright holder. To view a copy of this licence, visit http://creativecommons.org/licenses/by/4.0/.

\section{References}

1. Kulich DM, Gaggar SK, Lowry V, Stepien R. Acrylonitrile-Butadiene-Styrene polymers. Encyclopedia of polymer science and technology. New York: Wiley; 2002.

2. Rutkowski JV, Levin BC. Acrylonitrile-butadiene-styrene copolymers (ABS): pyrolysis and combustion products and their toxicity - a review of the literature. Fire Mater. 1986;10:93.

3. Greiner A, Wendorff JH. Electrospinning: a fascinating method for the preparation of ultrathin fibers. Angew Chem Int Ed. 2007; $46: 5670$

4. Liao X, Dulle M, de Souza e Silva JM, Wehrspohn RB, Agarwal S, Förster S, Hou H, Smith P, Greiner A. High strength in combination with high toughness in robust and sustainable polymeric materials. Science. 2019;366:1376.

5. Agarwal S, Wendorff JH, Greiner A. Use of electrospinning technique for biomedical applications. Polymer. 2008;49:5603.

6. Ding C, Fang H, Duan G, Zou Y, Chen S, Hou H. Investigating the draw ratio and velocity of an electrically charged liquid jet during electrospinning. RSC Adv. 2019;9:13608.

7. Jiang S, Agarwal S, Greiner A. Low-density open cellular sponges as functional materials. Angew Chem Int Ed. 2017;56:15520-38.

8. Zhang N, Qiao R, Su J, Yan J, Xie Z, Qiao Y, Wang X, Zhong J. Recent advances of electrospun nanofibrous membranes in the 
development of chemosensors for heavy metal detection. Small. 2017; 13:1604293.

9. Wu T, Ding M, Shi C, Qiao Y, Wang P, Qiao R, Wang X, Zhong J. Resorbable polymer electrospun nanofibers: history, shapes and application for tissue engineering. Chin Chem Lett. 2019. https:// doi.org/10.1016/j.cclet.2019.07.033.

10. Yao K, Chen J, Li P, Duan G, Hou H. Robust strong electrospun polyimide composite nanofibers from a ternary polyamic acid blend. Compos Commun. 2019;15:92.

11. Jiang S, Chen Y, Duan G, Mei C, Greiner A, Agarwal S. Electrospun nanofiber reinforced composites: a review. Polym Chem. 2018;9:2685.

12. Lv D, Zhu M, Jiang Z, Jiang S, Zhang Q, Xiong R, Huang C. Green electrospun nanofibers and their application in air filtration. Macromol Mater Eng. 2018;303:1800336.

13. Duan G, Liu S, Hou H. Synthesis of polyacrylonitrile and mechanical properties of its electrospun nanofibers. E-Polym.2018;18:569.

14. Cao M, Gu F, Rao C, Fu J, Zhao P. Improving the electrospinning process of fabricating nanofibrous membranes to filter PM2.5. Sci Total Environ. 2019;666:1011.

15. Han C, Wang Y, Lei Y, Wang B, Wu N, Shi Q, Li Q. In situ synthesis of graphitic-C3N4 nanosheet hybridized $\mathrm{N}$-doped $\mathrm{TiO}_{2}$ nanofibers for efficient photocatalytic $\mathrm{H}_{2}$ production and degradation. Nano Res.2015;8:1199.

16. Han J, Wang S, Zhu S, Huang C, Yue Y, Mei C, Xu X, Xia C. Electrospun core-shell nanofibrous membranes with nanocellulose-stabilized carbon nanotubes for use as high-performance flexible supercapacitor electrodes with enhanced water resistance, thermal stability, and mechanical toughness. ACS Appl Mat Interfaces. 2019; 11:44624-35.

17. Rao C, Gu F, Zhao P, Sharmin N, Gu H, Fu J. Capturing PM25 emissions from 3D printing via nanofiber-based air filter. Sci Rep. 2017;7:10366.

18. Calderon A, Que MC, Premacio A, Marasigan D. Morphological characterization of electrospun zeolite-filled acrylonitrile butadiene styrene fibrous membrane for lowpressured $\mathrm{CO}_{2}$ adsorption. Sustain Environ Res. 2014;24:365.

19. Chiu Y-J, Chi M-H, Liu Y-H, Chen J-T. Fabrication, morphology control, and electroless metal deposition of electrospun ABS fibers. Macromol Mater Eng. 2016;301:895.

20. Zulfi A, Hapidin DA, Munir MM, Iskandar F, Khairurrijal K. The synthesis of nanofiber membranes from acrylonitrile butadiene styrene (ABS) waste using electrospinning for use as air filtration media. RSC Adv. 2019;9:30741.

21. Smallwood I. Handbook of organic solvent properties. Oxford: Butterworth-Heinemann; 2012.
22. Viswanathan G, Kane DB, Lipowicz PJ. High efficiency fine particulate filtration using carbon nanotube coatings. Adv Mater. 2004; $16: 2045$.

23. Wang Y, Li W, Xia Y, Jiao X, Chen D. Electrospun flexible selfstanding [gamma]-alumina fibrous membranes and their potential as high-efficiency fine particulate filtration media. J Mater Chem A. 2014;2:15124.

24. Podgórski A, Bałazy A, Gradoń L. Application of nanofibers to improve the filtration efficiency of the most penetrating aerosol particles in fibrous filters. Chem Eng Sci. 2006;61:6804.

25. Shim WS, Leea DW. Quality variables of meltblown submicron filter materials. Indian J Fibre Text Res. 2013;38:132.

26. Yang S, Lee GWM. Filtration characteristics of a fibrous filter pretreated with anionic surfactants for monodisperse solid aerosols. J Aerosol Sci. 2005;36:419.

27. Hassan MA, Yeom BY, Wilkie A, Pourdeyhimi B, Khan SA. Fabrication of nanofiber meltblown membranes and their filtration properties. J Membr Sci. 2013;427:336.

28. Zhang Q, Welch J, Park H, Wu C-Y, Sigmund W, Marijnissen JCM. Improvement in nanofiber filtration by multiple thin layers of nanofiber mats. J Aerosol Sci. 2010;41:230.

29. Mei Y, Wang Z, Li X. Improving filtration performance of electrospun nanofiber mats by a bimodal method. J Appl Polym Sci. 2013;128:1089.

30. Wang N, Si Y, Wang N, Sun G, El-Newehy M, Al-Deyab SS, Ding B. Multilevel structured polyacrylonitrile/silica nanofibrous membranes for high-performance air filtration. Sep Purif Technol. 2014; 126:44.

31. Mao X, Si Y, Chen Y, Yang L, Zhao F, Ding B, Yu J. Silica nanofibrous membranes with robust flexibility and thermal stability for high-efficiency fine particulate filtration. RSC Adv. 2012;2:12216.

32. Hung $\mathrm{C}-\mathrm{H}$, Leung WW-F. Filtration of nano-aerosol using nanofiber filter under low Peclet number and transitional flow regime. Sep Purif Technol. 2011;79:34.

33. Liu B, Zhang S, Wang X, Yu J, Ding B. Efficient and reusable polyamide-56 nanofiber/nets membrane with bimodal structures for air filtration. J Colloid Interface Sci.2015;457:203.

34. Sambaer W, Zatloukal M, Kimmer D. 3D air filtration modeling for nanofiber based filters in the ultrafine particle size range. Chem Eng Sci. 2012;82:299.

35. Huang H-L, Yang S. Filtration characteristics of polysulfone membrane filters. J Aerosol Sci. 2006;37:1198.

36. Jiang S, Hou H, Agarwal S, Greiner A. Polyimide nanofibers by "green" electrospinning via aqueous solution for filtration applications. ACS Sustain Chem Eng. 2016;4:4797. 